\title{
An Exploration Into The Relationship Among EFL Learners' Emotional Intelligence, Self-Regulation, Autonomy, And Creativity
}

\author{
Mania Nosratinia ${ }^{1}$, Parisa Mirzaki ${ }^{2}$ \\ ${ }^{\text {I}}$ (Assistant Professor, Islamic Azad University at Central Tehran, Iran) \\ ${ }^{2}$ (MA in TEFL, Islamic Azad University at Central Tehran, Iran)
}

\begin{abstract}
The purpose of the present study was to investigate the relationship among EFL learners' Emotional Intelligence (EI), Self-Regulation (SR), Autonomy (AU), and Creativity (CR). To this end, 230 male and female EFL learners, ranging between 19 and 34 years old, majoring in General Linguistics, English Literature, and English Language Teaching at the Faculty of Foreign Languages, University of Tehran, Iran, were randomly selected. They were given four questionnaires: a questionnaire of EI, a questionnaire of $A U$, a questionnaire of $C R$, and Motivated Strategies for Learning Questionnaire (MSLQ). The results revealed that there is a significant relationship between EFL learners' EI and SR ( $r=.74, n=228, p<.05)$, EI and $A U(r=.605, n$ $=228, p<.05)$, EI and $C R(r=.702, n=228, p<.05)$, SR and $A U(r=.850, n=228, p<.05)$, SR and $C R(r$ $=.934, n=228, p<.05)$, and $A U$ and $C R(r=.887, n=228, p<.05)$. Considering $C R$ as the predicted variable of this study, it was confirmed that $S R$ is a better predictor of $C R$, and EI did not significantly contribute to $C R$.
\end{abstract}

Keywords: individual factors, emotional intelligence, self-regulation, autonomy, creativity

\section{Introduction}

Over the last few decades,language teaching, more particularly English Language Teaching (ELT), as a scientific and academic discipline has witnessed a strong, dynamic, and continuous evolution and development [1]. Concurrently, learner factors have received more and more attention, and the roles of many psychological and individual constructs in language learning are being investigated, e.g. learning strategies, learning styles, and critical thinking [2], [3]. In the same vein, [4] highlights the importance of studying the conventional psychological variables such as personality types, self-regulation, self-esteem, and creativity which are considered as individual differences that have great effect on language learning.

\section{Creativity (CR)}

In the field of language education, the development and amplification of creativity (CR), as a critical factor in the improvement of educational attainment and life skills are given a great value [5]. CR as [6] defines is complex in nature; so, different viewpoints have been put forward to explain the concept emphasizing different aspects of it. [7] Declare that CR is a multidimensional construct and may be measured as a personality trait or a creative style. However, [8] defines CR in terms of the problem-solving process rather than as a function of personal attributes. Moreover, some modern scholars define the concept of CR as something or some idea that is new and valuable [9], as opposed to [10] who believes that creative ability is analogous to a new combination in wordplay and metaphor.

Some scholars like [11] and [12] argued that personality characteristics and personal attributes such as high tolerance for ambiguity, willingness to take risks, and unconventionality are crucial factors in creativity and creative thought. Moreover, in most scientific resources, CR is considered as a common talent. The experts believe that all human beings have the talent to be creative and they seek to take many actions to develop their talents [13].

In addition to CR, emotions are assumed to have the potential influence on students' learning and cognitive functions [14]. As stated by [15], one of the individual factors which it is believed to affect academic achievement is Emotional Intelligence (EI).

\section{Emotional Intelligence (Ei)}

EI was defined originally by [16] as "the ability to monitor one's own and others' feelings and emotions, to discriminate among them and to use this information to guide one's thinking and actions" (p. 189). [17]Conceptualizes EI as a set of personality traits and abilities that predict emotional and social adaptation 
within environments. [18] believed that EI, consisting of emotional self-awareness as well as various skills, stems from effective use or regulation of emotions such as effective interpersonal relationships, problem solving, and stress tolerance. Moreover, according to [19], EI consists of interaction between emotion and cognition that leads to appropriate functioning. An important point is that EI is teachable and could be developed properly [20]. Therefore, it appears that those educational instructions that pay attention to EI and the way it can be boosted, in addition to other mental and cognitive factors, would make positive changes in learners' academic achievement and quality of life [15]. Therefore, inspecting the association between EI and other mental, psychological and/or personal factors seems to be a legitimate attempt in the TEFL domain.

\section{Self-Regulation (Sr)}

Self-Regulation (SR) as one of these psychological factors seems to have considerable influence on the learning process [21]. SR or self-regulated learning is "an active, constructive process whereby learners set goals for their learning and then attempt to monitor, regulate, and control their cognition, motivation, and behavior, guided and constrained by their goals and the contextual features in the environment" [22].

Another definition of SR comes from [21] who defines the self-regulated learning as "ways of tackling the learning task at hand and managing the self in overseeing the learning process under the constraints of the learning situation and learning context for the purpose of learning success" (p. 2). It is believed that SR, as an innate capacity, fuels learners' efforts for searching and applying personalized strategic mechanisms [23] which might enhance the effectiveness of their L2 learning process.

Since self-regulated learning is a difficult construct to define theoretically and operationalize empirically, there are many models of SR that propose different attributes [24]. According to [25], all models of self-regulated learning assume that: firstly, learners are active participants in their learning; secondly, the processes involve monitoring, controlling, and evaluating one's own affects, motivation, cognition, and behavior as well as some aspects of the learning environment; thirdly, self-regulated learning is directed toward personally set goals with which learners can compare their progress for determining whether the process should be maintained or adapted.

\section{Autonomy (AU)}

Moreover, recently the initiation of postmethod and the shift toward a learner-centered methodology in educational systems have resulted in focusing on self-education and transferring responsibilities from teacher to learner in learning process. This new trend has led to a sharp focus on Autonomy (AU) in learning [3]. AU according to [26] is defined as "developing strategies, techniques or materials in order to promote individual self-development" (p. 45). Moreover, [27] AU as "...the competence to develop as a self-determined, socially responsible and critically aware participant in (and beyond) educational environments, within a vision of education as (inter) personal empowerment and social transformation" (p. 1). They declare that it is the ability to develop appropriate strategies and prepare individuals for life-long learning. "A crucial task of the teacher wishing to promote learner $\mathrm{AU}$ is to help learners take responsibility for their learning, and to bring about necessary attitudinal changes in them" [28].

Based on the points stated, there seems to be a theoretical association among AU, SR, EI, and CR which are believed to affect the process of learning. This point justifies the attempt to systematically investigate the interrelationships among these four factors. To fulfill this objective, the following research questions were proposed:

1. Is there any significant relationship between EFL learners' emotional intelligence and self-regulation?

2. Is there any significant relationship between EFL learners' emotional intelligence and autonomy?

3. Is there any significant relationship between EFL learners' emotional intelligence and creativity?

4. Is there any significant relationship between EFL learners' self-regulation and autonomy?

5. Is there any significant relationship between EFL learners' self-regulation and creativity?

6. Is there any significant relationship between EFL learners' autonomy and creativity?

Presuming a significant relationship among the four variables, the following research question was formulated:

7. Is there any significant difference among EFL learners' emotional intelligence, self-regulation and autonomy in predicting their creativity?

\section{Participants}

\section{Method}

Two hundred and thirty EFL learners (male, 36\%, and female, $64 \%$ ) ranging between 19 and 34 years old, majoring in General Linguistics, English Literature, and English Language Teaching at the faculty of foreign languages, University of Tehran, Iran were randomly selected. 


\section{Instrumentation}

In order to accomplish the purpose of the study, the Persian versions of the following four questionnaires were utilized:

\section{Emotional Quotient Inventory (Bar-On Eq-I)}

Bar-On Emotional Quotient Inventory (EQ-i),designed by [29], is a self-report measure of emotionally and socially intelligent behavior that provides an estimate of emotional-social intelligence. It consists of 133 items which measures five broad areas of skills or competencies (Intrapersonal, Interpersonal, Adaptability, Stress Management, and General Mood) and 15 factorial components [18], as cited in [30].

The items are in the form of short sentences and employ a five-point response scale (never, seldom, usually, often, and always) with a textual response format ranging from "very seldom or not true of me" (1) to "very often true of me or true of me" (5). Bar-On administrated this questionnaire to 3831 people in six countries between both sexes.

However, as the original questionnaire was too long (133 items), lately a 90 item version was published, [31]. As the result, the scores could range from 90 to 450. Some of the questions in the questionnaire (questions 2, 11, 12, 15, 17, 18, 19, 20, 21, 22, 26, 27, 33, 34, 35, 36, 37, 40, 41, 45, 48, 50, 52, 56, 58, 61, 63, $64,67,71,72,75,77,78,79,80,82,84,86,87,90)$ were negatively worded to examine students' attention to the questionnaire, and they were scored reversely. For the EQ-i [29] high and low scores exceeding the mean or falling below the mean by 1 SD (15 points) are considered to be within the normal range. The EQ-i is suitable for individuals in 17 year and older [32] and takes approximately forty minutes to complete.

In this study, to avoid cross-cultural differences and probable misunderstanding regarding the content of the questionnaire the translated Persian version of this questionnaire was used. The Persian EQ-i (90 items) has been translated and piloted by [33]. The reliability of the questionnaire, in this study, was estimated to be 0.91 using the Cronbach's alpha coefficient, which demonstrated a fair degree of reliability.

\section{Motivated Strategies For Learning Questionnaire (Mslq)}

MSLQ was used in this study in order to measure the degree of self-regulation in participants.It is a self-report, Likert-scaled instrument designed to assess students' motivational orientations and their use of different learning strategies.

It was developed at the National Center for Research to Improve Postsecondary Teaching and Learning at the University of Michigan by [34]. The Original form of MSLQ consists of 81 Likert-type items divided into two sections: motivation (31 items) and learning strategies (50 items). According to [34], the MSLQ scales "are designed to be modular and can be used to fit the needs of researchers" (p. 3). Therefore, based on the requirements of this study, an adapted version of MSLQ was selected. It contains 47 items which are divided into eight subscales including task value (6 items), control of learning beliefs (4 items), elaboration (6 items), metacognitive self-regulation (12 items), time and study environment ( 8 items), effort regulation (4 items), help seeking (4 items), and peer learning ( 3 items).

There were eight items that had to be reverse-scaled including 17, 24, 31, 35, 36, 37, 39, and 44. For the reversed items the values are $(1=7,2=6,3=5,4=4,5=3,6=2, \& 7=1)$. In this regard, the result could vary from 47 to 329 , and the higher the mark, the more self-regulated was the participant.The respondents were supposed to answer the questions in 25 minutes.

This instrument is originally written in English. To avoid any linguistic confusion and misunderstanding, the translated Persian version of the questionnaire by [35] was used in order to make sure of the participants' full comprehension.The reliability of MSLQ, in this study, was estimated to be .81 using the Cronbach's alpha coefficient, which demonstrated a fair degree of reliability.

\section{Learner Autonomy Questionnaire (Laq)}

The questionnaire contains 52 items and was designed by [36] who state that this designing is strongly influenced by [37] definition of AU. [37], as cited in [36] defines AU as "the ability to take charge of one's own learning is to have and to hold the responsibility for all the decisions concerning all aspects of this learning" ( $p$. 249).[37]According to [38] argues that ability and responsibility are functioning in five principal areas that are: "determining objectives; defining contents, and progressions; selecting methods and techniques to be used; monitoring the procedure of acquisition; and evaluating what has happened" (p. 249). All these notions of ability and responsibility are incorporated in the questionnaire. The instrument has four sections:

- The first section (13 items) focuses on examining the students' views of their responsibilities and those of their teachers.

- The second section (11 items) explores the students' confidence in their ability to operate autonomously.

- The third section (1 item) aims to measure the levels of student motivation to learn English. 
- The fourth section (27 items) investigates the students' practice of autonomous learning in the form of both inside and outside class activities.

Respondents were asked to indicate their answers in 20 minutes in a Likert scale, sequentially assigning values of 1,2,3,4, and 5 to options of "not at all", "a little", "some", "mainly", and "completely" in section one; counting 1 for "very poor" to 5 for "very good" in section two; setting 5 to 1 beside the first to the last choices in section three; and attributing values of 1,2,3, and 4 to options of "never", "rarely", "sometimes", and "often" in section four. In this regard, the result can vary from 52 to 233.

In this study the Persian version of this questionnaire that has been translated and validated by [38] was employed to make sure of the full comprehension of the questions by the participants. The reliability of AU questionnaire, in this study, was estimated to be .79 using the Cronbach's Alpha which demonstrated a good degree of reliability.

\section{The Abedi-Schumacher Creativity Test (Act)}

This questionnaire was designed by [39] and is called the Abedi-Schumacher Creativity Test or the ACT (as cited in [40]). The ACT consists of 60 multiple-choice items used for establishing the scores of the four traits underlying creative thinking, Fluency (22items); Flexibility (11items); Originality (16 items); and Elaboration (11 items).

Each item has three options ranging from least to most creative responses with a range of scores between $0-2$. Therefore, the ultimate score is estimated in the possible range of 0 to120, and participants are supposed to answer the items in 60 minutes. ACT was translated validated by [41]. As reported by [41], ten nonfunctioning items were excluded from the questionnaire because they either did not load on any of the factors or loaded simultaneously on a couple of factors.

The 50 multiple-choice items of this questionnaire have three options ranging from least to most creative responses with a range of scores between 0-2; therefore, the scores of the Persian Creativity Test could range from 0 to 100 , and the participants are allocated 50 minutes to respond to the questionnaire.In this study, to avoid any misinterpretation, this Persian version was used.The reliability of the CR questionnaire in this study was estimated to be 0.77 using the Cronbach's alpha coefficient.

\section{Procedure}

Before administering the packages of the questionnaires, the researchers intentionally randomized the order of questionnaires in each package to control for the impact of order on the completion process. Then, these packages were administered to 300 male and female students majoring in General Linguistics, English Literature, and English Language Teaching at University of Tehran in two sessions and during two semesters.

Before administrating the questionnaires, the participants were fully briefed on the process of completing the questionnaires. The researchers observed the process of filling out randomly to make sure that they were capable to fully understand the questions and responses. The completed questionnaires were collected and scored by the researchers. From the initial 300 administered questionnaires, a number of 230 sets answered for all the four questionnaires, were considered for statistical analyses regarding the relationship among the variables.

\section{Conclusion}

Before discussing the results, a review of the preliminary assumptions is needed.

\section{Testing The Preliminaryassumptions}

This study set out to investigate the relationship among EFL learners' EI, SR, AU, and CR. In order to answer the research questions, the data were analyzed through Pearson's correlation and regression analyses. So, three main assumptions of interval data, independence of subjects (i.e. their performance on the test should not affected by the performance of other students), and normality were checked.

The present data were measured on an interval scale, and the participants performed independently on the questionnaires. Moreover, the assumption of normality was met; the values of skewness and kurtosis ratios were within the ranges of \pm 1.96 .

\section{The First Research Question}

$\mathbf{Q}_{1}$ :Is there any significant relationship between EFL learners' emotional intelligence and self-regulation? The results of the Pearson's correlation $(\mathrm{r}(228)=.74, \mathrm{P}<.05$, representing a large effect size) indicated that there was a significant relationship between EFL learners' emotional intelligence and self-regulation (Table 1). 
Table 1: Pearson's Correlation; Emotional Intelligence and Self-Regulation

\begin{tabular}{l|l|l}
\hline & & FmotionalIntellioence \\
\hline Self-Regulation & Pearson Correlation & $.741^{* *}$ \\
\hline & Sig. (2-tailed) & .000 \\
\hline & $\mathrm{N}$ & 230 \\
\hline$* *$. Correlation is significant at the 0.01 level (2-tailed). \\
\hline
\end{tabular}

As table 1 shows, there was a positive relationship between the two variables. The value of correlation $(0.74)$ indicates how closely emotional intelligence and self-regulation are related.

\section{The Second Research Question}

$\mathrm{Q}_{2}$ : Is there any significant relationship between EFL learners' emotional intelligence and autonomy?

The results of the Pearson's correlation $(\mathrm{r}(228)=.605, \mathrm{P}<.05$, representing a large effect size) indicated that there was a significant relationship between EFL learners' emotional intelligence and autonomy (Table 2).

Table 2: Pearson's Correlation; Emotional Intelligence and Autonomy

\begin{tabular}{l|l|l}
\hline & & EmotionalIntelligence \\
\hline Autonomy & Pearson Correlation & $.605^{* *}$ \\
\hline & Sig. (2-tailed) & .000 \\
\hline & $\mathrm{N}$ & 230 \\
\hline \multirow{2}{*}{$* *$ Correlation is significant at the 0.01 level (2-tailed). }
\end{tabular}

Table 2 reveals that emotional intelligence and autonomy with the value of correlation $(0.60)$ are related.

\section{The Third Research Question}

$\mathbf{Q}_{3}$ : Is there any significant relationship between EFL learners' emotional intelligence and creativity?

The results of the Pearson's correlation $(\mathrm{r}(228)=.702, \mathrm{P}<.05$, representing a large effect size) indicated that there was a significant relationship between EFL learners' emotional intelligence and creativity (Table 3 ).

Table 3: Pearson's Correlation; Emotional Intelligence and Creativity

\begin{tabular}{l|l|l}
\hline \multicolumn{2}{|c|}{} & EmotionalIntelligence \\
\hline Creativity & Pearson Correlation & $702^{* *}$ \\
\cline { 2 - 3 } & Sig. (2-tailed) & .000 \\
\cline { 2 - 3 } & N & 230 \\
\hline
\end{tabular}

**. Correlation is significant at the 0.01 level (2-tailed).

As table 3 shows, there was a significant relationship between emotional intelligence and creativity. The value of correlation (0.70) indicates how closely emotional intelligence and creativity are related.

Thus, it can be concluded thatthere issignificant relationship among EFL learners' emotional intelligence, selfregulation, autonomy, and creativity.

\section{The Fourth Research Question}

$\mathbf{Q}_{4}$ : Is there any significant relationship between EFL learners' self-regulation and autonomy?

As shown in Table 4 the results of the Pearson correlation $(\mathrm{r}(228)=.850, \mathrm{P}<.05$, representing a large effect size) indicated that there was a significant relationship between EFL learners' self-regulation and autonomy.

Table 4: Pearson's Correlation; Self-Regulation and Autonomy

\begin{tabular}{lll}
\hline & & Self-Regulation \\
\hline Autonomy & Pearson Correlation & $.934^{* * *}$ \\
& Sig. (2-tailed) & .000 \\
& $\mathrm{~N}$ & 230 \\
\hline
\end{tabular}

**. Correlation is significant at the 0.01 level (2-tailed). 


\section{The Fifth Research Question}

$\mathbf{Q}_{5}$ : Is there any significant relationship between EFL learners' self-regulation and creativity?

The results of the Pearson's correlation ( $\mathrm{r}(228)=.934, \mathrm{P}<.05$, representing a large effect size) indicated that there was a significant relationship between EFL learners' self-regulation and creativity (Table 5).

Table 5: Pearson's Correlation; Self-Regulation and Creativity

\begin{tabular}{lll}
\hline & & Self-Regulation \\
\hline Creativity & Pearson Correlation & $.934^{* *}$ \\
& Sig. (2-tailed) & .000 \\
& $\mathrm{~N}$ & 230 \\
\hline
\end{tabular}

**. Correlation is significant at the 0.01 level (2-tailed).

\section{The Sixth Research Question}

$\mathbf{Q}_{6}$ : Is there any significant relationship between EFL learners' autonomy and creativity?

The results of the Pearson's correlation ( $\mathrm{r}(228)=.887, \mathrm{P}<.05$, representing a large effect size) indicated that there was a significant relationship between EFL learners' autonomy and creativity (Table 6).

Table 6: Pearson's Correlation; Autonomy and Creativity

\begin{tabular}{lll}
\hline & & Self-Regulation \\
\hline Creativity & Pearson Correlation & $.887^{* *}$ \\
& Sig. (2-tailed) & .000 \\
& $\mathrm{~N}$ & 230 \\
\hline
\end{tabular}

**. Correlation is significant at the 0.01 level (2-tailed).

\section{The Seventh Research Question}

Q7 $_{7}$ Is there any significant difference among EFL learners' emotional intelligence, self-regulation and autonomy in predicting their creativity?

A linear regression analysis through the Enter Method was run to predict EFL learners' creativity by using emotional intelligence, self-regulation and autonomy. The Enter Method was selected because it is the only estimation method that enables the researchers to compare two or more predictors. Based on the results displayed in Table 7, it can be concluded that the EFL learners' emotional intelligence, self-regulation and autonomy can predict 90.5 percent of their creativity $\left(\mathrm{R}=.951, \mathrm{R}^{2}=.905\right)$. The Durbin-Watson value of 2.10 indicated that there were not serial correlations between errors, an assumption that must be met when running regression. Also, [42] believes that Durbin-Watson values between 1 and 3 are acceptable.

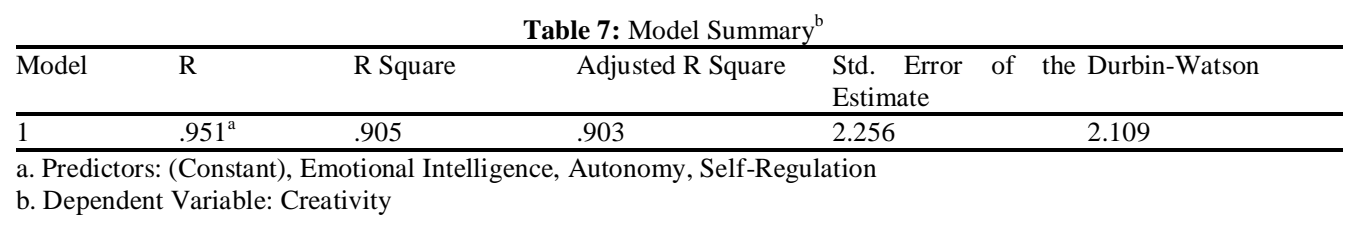

The results of the ANOVA test of significance of the regression model $(\mathrm{F}(3,226)=715.64, \mathrm{P}<.05)$ indicated that the regression model can significantly predict creativity (Table 8).

\begin{tabular}{|c|c|c|c|c|c|c|}
\hline Model & & Sum of Squares & $\mathrm{df}$ & Mean Square & $\mathrm{F}$ & Sig. \\
\hline \multirow[t]{3}{*}{1} & Regression & 10929.489 & 3 & 3643.163 & 715.642 & $.000^{\mathrm{b}}$ \\
\hline & Residual & 1150.511 & 226 & 5.091 & & \\
\hline & Total & 12080.000 & 229 & & & \\
\hline
\end{tabular}

Table 9 displays the results for the regression coefficients. The most important coefficients are the standardized beta values, t-statistics and their probability.

Based on the results of the standardized beta values it can be concluded that self-regulation (beta = $.617, \mathrm{t}=13.33, \mathrm{P}<.05$ ) is a better predictor of creativity than autonomy (beta $=.33, \mathrm{t}=8.68, \mathrm{P}<.05$ ). The emotional intelligence did not significantly contribute to creativity (beta $=.04, \mathrm{t}=1.29, \mathrm{P}>.05$ ).

Table 9: Coefficients ${ }^{\mathrm{a}}$

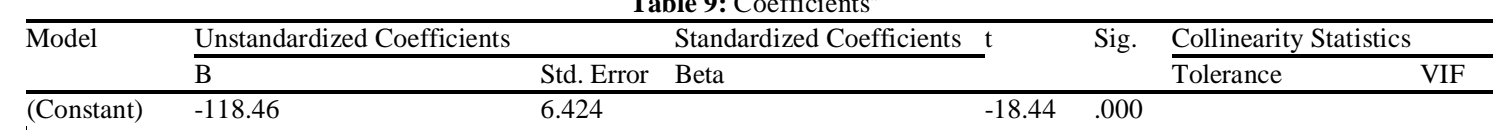


An Exploration into the Relationship among EFL Learners' Emotional Intelligence, Self...

\begin{tabular}{|c|c|c|c|c|c|c|c|}
\hline Autonomy & .191 & .022 & .339 & 8.680 & .000 & .277 & 3.612 \\
\hline $\begin{array}{l}\text { Self- } \\
\text { Regulation }\end{array}$ & .460 & .034 & .617 & 13.332 & .000 & .197 & 5.083 \\
\hline $\begin{array}{l}\text { Emotional } \\
\text { Intelligence }\end{array}$ & .008 & .006 & .040 & 1.296 & .196 & .448 & 2.232 \\
\hline
\end{tabular}

The last two columns, tolerance and VIF (variance inflation factor), test the lack of multicollinearity assumption. If the values of tolerance are higher than .10 and the values of VIF are lower than 10, it can be concluded that there were not too high correlation among all variables. In other words the assumption of lack of multicollinearity was met.

\section{Discussion And Conclusion}

The findings of the study show that there is a significant relationship among the above-mentioned variables. Based on the results, EFL learners' emotional intelligence showed significant correlations with selfregulation $(\mathrm{r}(228)=.74, \mathrm{P}<.05)$ which indicated that emotional intelligence and self-regulation are closely related. Considering that no previous studies were found to explore the relationship between EI and SR, the result cannot be compared.

Based on the results of this study, the relationship between EFL learners' emotional intelligence and autonomy turned out to be significant $(\mathrm{r}(228)=.605, \mathrm{P}<.05)$ which indicated that EI and AU are closely related. This finding was also in line with the results of previous researches that found links between these two variables. A study conducted by [43], explored the relationship between EI and AU. The sample of the study consisted of 129 undergraduate students of Arts College in the northeastern U.S.A. The obtained results indicated a positive strong relationship between learners' $\mathrm{EI}$ and $\mathrm{AU}(\mathrm{r}=.52 ; \mathrm{p}=.00 ;<.01)$.

Moreover, the results of this study revealed that EFL learners' emotional intelligence showed a significant relationship with creativity $(\mathrm{r}(228)=.702, \mathrm{p}<.05)$. The mentioned result is in line with the findings of [44].

[44]Investigated the impact of emotional intelligence and creativity among 100 university students in various disciplines of the humanities. This result is also supported by the findings of [45], who investigated a relationship between emotional intelligence and creativity, among 214 students of a girl high school in Baft in academic year 2008-2009. The instruments used in this research were Bar-on's EI inventory and [46]. The results of the research considering significance level $(\mathrm{p} \leq 0 / 01)$ and the obtained Pearson's coefficient $(r=$ 0.562 ), show that there is significant and positive relation between emotional intelligence and creativity of students.

With respect to the findings of the current study EFL learners' self-regulation showed a significant relationship with autonomy $(\mathrm{r}(228)=.850, \mathrm{P}<.05)$. Considering that no previous studies were found to explore the relationship between self-regulation and autonomy, the result cannot be compared.

Also, the results of this study showed that, students with positive levels of self-regulation proved to be more creative in learning process $(\mathrm{r}(228)=.934, \mathrm{P}<.05)$. This result is also consistent with the results of the study conducted by [47]. [47]Investigated the relationship between self-regulation and creativity. The participants of this study includes 1976 graduated and under graduated students of Farhangian University in west [46] and self-regulation questionnaire of [48] were used in this study. Pearson's Correlation Coefficient, Multivariate Regression Analysis and t-test of distinct groups were used in order to analyze the data. The result showed that there is a positive and significant relationship between self-regulation and student's creativity.

Furthermore, the results of the present study showed a statistically significant relationship between EFL learners' autonomy and creativity $(\mathrm{r}(228)=.887, \mathrm{P}<.05)$. This result is in line with the findings of [49] who investigated the relationship between creativity and autonomy among EFL learners. In their study, a group of 182 male and female EFL learners was participated. The results indicated that there is a significant and positive relationship between EFL learners' creativity and autonomy $(r=0.665, \mathrm{p}<0.05)$.

Based on the results of the current study it can be concluded that the four variables, emotional intelligence, self-regulation, autonomy, and creativity, are closely and significantly interconnected. In addition, EFL learners' self-regulation makes the strongest statistically significant unique contribution to explaining creativity. It was also observed that EFL learners' emotional intelligence, self-regulation, and autonomy can predict 90.5 percent of their creativity $\left(\mathrm{R}=.951, \mathrm{R}^{2}=.905\right)$

Based on the results of the standardized beta values it can be concluded that self-regulation (beta = $.617, \mathrm{t}=13.33, \mathrm{P}<.05$ ) is a better predictor of creativity than autonomy (beta $=.33, \mathrm{t}=8.68, \mathrm{P}<.05$ ). The emotional intelligence did not significantly contribute to creativity (beta $=.04, \mathrm{t}=1.29, \mathrm{P}>.05$ ).

The findings of this study have some implications for EFL teachers.EFL teachers can provide students with ample opportunity to distance themselves from their traditional learning habits. With regard to the findings of the study, teachers can provide students with helpful guidelines to inform them of the ways through which EI, SR, AU, and CR can contribute to learning more independently, lastingly, and effectively. Due to the fact that 
language learning is a multidimensional phenomenon [50], not only language teachers, but also language learners are required to play their roles properly in order to facilitate and optimize this complicated process. Therefore, results of the current study have implications for language learners, encouraging them to become more creative, self-regulated, and autonomous about their learning activities. When students are empowered with these variables, they can become confident, independent, and autonomous learners. In addition, curriculum developers and material producers can design a better program, appropriate materials and tasks that will promote a more autonomous and creative language learning atmosphere which can train self-regulated learners.Moreover, when relevant training hints or motives regarding EI, SR, AU, CR are inserted in appropriate parts of a program and course book, teachers are provided with a powerful device to optimize language learning activities, and learners can benefit a more detailed EFL context.

\section{References}

[1]. P. R., Howatt, \&H. G.Widdowson, A history of English language teaching (Oxford: Oxford University Press, 2004).

[2]. A.Albert, Learner's creativity as a potentially important variable: Examine the relationships between learner creativity, language aptitude and level of proficiency. In M. Nikolove, \& J. Horvath (Eds.). Empirical Studies in English Applied Linguistics, Hungary, Eotous University, 2006,77-98.

[3]. M. Nosratinia, \&A.Zaker, Autonomous learning and critical thinking: Inspecting the association among EFL learners. Paper presented at the First National Conference on Teaching English, Literature, and Translation, Shiraz University, Shiraz, Iran, 2013a. Retrieved September 6, 2013 from http://www.civilica.com/Paper-TELT01-TELT01_226.html

[4]. Z. Dörnyei, The psychology of the language learner. Individual differences in second language acquisition. New Jersey: Lawrence Erlbaum Associates. Hungary, Eotous University, 2005.

[5]. K. P. Agrawal, Development of creativity in Indian schools: Some related issues. New Delhi: Concept Publishing Company, 1992.

[6]. M. R. Sarsani, Creativity in schools. New Delhi: Sarup \& Sons, 2006.

[7]. O.Matsouka, E.Trevlas, \&E.Zachopoulou, Relationship between playfulness and motor creativity in preschool children. Early Childhood Development and Care, 173(5), 2003, 535-543.

[8]. R. K. Sawyer, Emergence in creativity and development. In R. K. Sawyer, V. John-Steiner, S. Moran, R. Sternberg, D. H. Feldman, M. Csikszentmihalyi, \& J. Nakamura,Creativity and Development, New York: Oxford, 2003, 12-60.

[9]. M. A. Boden, The Creative mind: Myths and mechanisms ( $2^{\text {nd }}$ ed.). London/New York: Routledge, 2004.

[10]. R.Carter, Language and creativity: The art of common talk.New York: Routledge, 2004.

[11]. R. J., Sternberg, \&T. I. Lubart, Defying the crowd: Cultivating creativity in a culture of conformity. New York: Free Press, 1995.

[12]. M.Runco, Creativity. Annual Review of Psychology, 55,2004, 657-687.

[13]. A.Asadi, What is creativity and how can make students creative? School Management Development, 4 (5), $2006,18-27$.

[14]. Z.Dörnyei, \&P. Skehan, Individual differences in second language learning. In C. J. Doughty and M. H. Long (Eds.): The Handbook of Second Language Acquisition. Oxford: Blackwell, 2003. Retrieved May 16, 2012, from http://www.nottingham.ac.uk/ aezweb/research/cral/

[15]. H., Yazici, S., Seyis, \&F. Altun, Emotional intelligence and self- efficacy beliefs as predictors of academic achievement among high school students. Procedia Social and Behavioral Sciences, 15,2011, 2319-2323.

[16]. P., Salovey, \&J.Mayer, (1990). Emotional intelligence. Imagination, Cognition and Personality, 9, $1990,185-211$.

[17]. R.Bar-On, The Bar-On model of emotional-social intelligence (ESI). Psicothema Special Issue on Emotional Intelligence, 17, 2005, $1-28$.

[18]. R.Bar-On, Emotional and social intelligence. Insights from the emotional quotient inventory (EQ-I). In: R. Bar-On \& J. D. A. Parker, (Eds.), Handbook of Emotional Intelligence, Jossey-Bass, San Francisco, 2000, 363-388.

[19]. P., Salovey, \&D.Grewal, The science of emotional intelligence. Current Directions in Psychological Science, 14,2005, $281-285$.

[20]. J. D., Mayer, \&P.Salovey, (2004). Social intelligence [Emotional Intelligence]. In C. Peterson \& M. E. P. Seligman (Eds.), Character strengths and virtues, Washington, DC: American Psychological Association, 2004, 337-353.

[21]. Y.Gu, Advance review: A book on teaching and researching language learning strategies. Wellington University, Wellington: New Zealand, 2010

[22]. P. R. Pintrich, (2000). The role of goal orientation in self-regulated learning. In M. Boekaerts, P. R. Pintrich, \& M. Zeidner (Eds.), Handbook of Self-Regulation, San Diego: Academic Press, 2000, 451-502.

[23]. W., Tseng, Z., Dörnyei, \&N.Schmitt, A new approach to assessing strategic learning: The case of self-regulation in vocabulary acquisition. Applied Linguistics, 27,2006, 78-102.

[24]. J. Zimmerman, Theories of self-regulated learning and academic achievement: An overview and analysis. In B. J. Zimmerman \& D. H. Schunk (Eds.), Self-RegulatedLearning and Academic Achievement: Theoretical Perspectives (2 ${ }^{\text {nd }}$ ed.) Mahwah, NJ: Erlbaum, 2001, 1-37.

[25]. P. R. Pintrich, A conceptual framework for assessing motivation and self-regulated learning in college students. Educational Psychology Review, 16,2004, 385-407.

[26]. Pennycook, Cultural alternatives and autonomy .In P. Benson \& P. Voller (Eds.), Autonomy and independence in language learning, New York: Longman, 1997, 35-53.

[27]. M., Jiménez Raya, T., Lamb, \&F.Vieira, Pedagogy for autonomy in language education in Europe -Towards a framework for learner and teacher development,Dublín: Authentik, 2007.

[28]. Kumaravadivelu, Beyond methods: Macro strategies for language teaching. New Haven, C.T.: Yale University Press, 2003.

[29]. R.Bar-On, The Emotional Quotient Inventory (EQ-i): A test of emotional intelligence. Toronto: Multi-Health Systems, 1997

[30]. M., Fahim, \&R.Pishghadam, On the role of emotional, psychometric, and verbal intelligences in the academic achievement of university students majoring in English language. Asian EFL Journal, 9, 2007, 240-253.

[31]. R. Samouei, Standardization of Bar-On emotional intelligence test. Tehran: Sina Research Institution on behavioral sciences, 2003.

[32]. R., Bar-On, J. D. A., Parker, (Eds.) The handbook of emotional intelligence: Theory, development, assessment, and application at home, school and in the workplace. San Francisco: John Wiley \& Sons, 2000.

[33]. S.Ghods, The effect of emotional intelligence on reading comprehension and structural ability of Iranian intermediate EFL students, unpublished master's thesis, Islamic Azad University of Garmsar, Garmsar, Iran, 2007.

[34]. R. P.,Pintrich, A. F. D., Smith, T., Garcia, \&W.McKeachie, A manual for the use of the motivated strategies for learning questionnaire (MSLQ). National center for research to improve post-secondary teaching and learning, Ann Arbor, HI, 1991. 
[35]. A.Navidi, The significant study of common and special of former academic function variables academic self-concept and general intelligence in academic achievement prediction of students. The Quarterly Journal of Education, 76,2003, 97-129.

[36]. M., Spratt, G., Humphreys, \&V.Chan, Autonomy and motivation. Which comes first? Language Teaching Research, 6, 3, 2002, 245-266.

[37]. H.Holec, Autonomy and foreign language learning,Oxford: Pergamon, 1981.

[38]. M. Fahim., \&R.Behdani, Critical thinking ability and autonomy of Iranian EFL learners. American Journal of Scientific Research, $29,2011,59-72$

[39]. H. F., O' Neil, J., Abedi, \&C. D. Spielberger, (1994). The measurement and teaching of creativity. In H. F. O' Neil \& M. Drillings (Eds.), Motivation: Theory and research ,Hillsdale, NJ: Lawrence Erlbaum Associates, 1994, 245-264.

[40]. J. Cropley, Defining and measuring creativity: Are creativity tests worth using? Roper Review, 23(2), 2000, $72-79$.

[41]. A.Zaker, (). The relationship among EFL learners' creativity, critical thinking, and autonomy, unpublished master's thesis. Islamic Azad University at Central Tehran, Iran, 2013.

[42]. A.Filed, Discovering statistics using IBM SPSS: Statistics for statistics. (4 ${ }^{\text {th }}$ ed.). London: SAGE Publications, 2013.

[43]. K. A.,Buvoltz, F. J., Powell, A. M., Solan, \&G. J.,Longbotham, Exploring emotional intelligence, learner autonomy, and retention in an accelerated undergraduate degree completion program. New Horizons in Adult Education and Human Resource Development, 22(3/4), 2008, 26-43. Retrieved November 14, 2013, from http://education.fiu.edu/newhorizons

[44]. K., Ghaffari1, R. M., Sarmadi, N., Safari, \&M.Shahsavari,The Impact of emotional intelligence and creativity among the university students. Journal of Basic and Applied Scientific Research, 3(1), 2012, 792-794. Retrieved November 15, 2013, fromwww.textroad.com

[45]. R., Dadvar, M., Mohamadrezaii, \&M. Habibi Fathabadi, The Relationship between emotional intelligence and creativity of female high school students in Baft city.Journal of Basic and Applied Scientific Research, 2(4), 2012, 4174-4183. Retrieved May 16, 2012, from www.textroad.com

[46]. J. Abedi, Standardized achievement tests and English language learners: Psychometrics issues. Educational Assessment, 8, 2002, 231-257.

[47]. sh.Rezaei, Analyzing the influential elements (e.g.,, self-regulation, information technology and life skills) on creativity of Farhangian university students of west Azarbayjan for the term date 91-92.Unpublished master's thesis, Islamic Azad University, Urmia, Iran, 2013. Retrieved March 7, 2013 from http://azarbaijaniran.blogfa.com/

[48]. Carey, K. B., Neal, D. J., \& Collins, S. E. , A psychometric analysis of the self-regulation questionnaire. Addictive Behaviors, 29, 2004, 253-260. Retrieved June 1, 2013, from http://dx.doi.org/10.1016/j.addbeh.2003.08.001, PMid:14732414

[49]. M., Nosratinia, \&A.Zaker, Creativity and autonomy: Connections for language learning. Paper presented at the Second ELT Conference, Allameh Tabataba'i University, Tehran, Iran, 2013b.

[50]. C.Stebbins, Culture-specific perceptual-learning style preferences of postsecondary students of English as a second language. In J. Reid (Eds.) Learning Styles in the ESL/EFL Classroom. Boston: Heinle, 1995, 108-117). 